\title{
Assessing the efficiency of aggregate low impact development (LID) at a small urbanized sub-catchment under different storm scenarios
}

\author{
Dong Jin Jeon ${ }^{\mathrm{a}}$, Seo Jin $\mathrm{Ki}^{\mathrm{a}}$, Sang-Soo Baek ${ }^{\mathrm{b}}$, YoonKyung $\mathrm{Cha}^{\mathrm{c}}$, Kyung Hwa Cho ${ }^{\mathrm{b}}$, \\ Kwang-Sik Yoon ${ }^{\mathrm{d}}$, Hyun Suk Shine, Joon Ha Kim, ${ }^{\mathrm{a}, *}$ \\ ${ }^{a}$ School of Earth Sciences and Environmental Engineering, Gwangju Institute of Science and Technology (GIST), Gwangju 61005, \\ Korea, email: joonkim@gist.ac.kr (J.H. Kim) \\ ${ }^{b}$ School of Urban and Environmental Engineering, Ulsan National Institute of Science and Technology (UNIST), Ulsan 44919, Korea \\ 'Department of Environmental Engineering, University of Seoul, Seoul 02504, Korea \\ ${ }^{\circledR}$ Department of Rural and Biosystems Engineering, Chonnam National University, Gwangju 61186, Korea \\ 'School of Urban, Architecture and Civil Engineering, Pusan National University, Busan 46241, Korea
}

Received 5 February 2017; Accepted 13 April 2017

\begin{abstract}
A B S T R A C T
While the size of single low impact development (LID) unit determines the performance in attenuating water quantity and quality from storm runoff, the performance of multiple LID units is sensitive to both their size and arrangement order. This study describes a methodology to obtain the best performance for multiple LID units under varying by time-to-peak of storm with the same intensity and duration using storm water management model (SWMM), a popular model for rainfall-runoff and water quality simulation. The hypothetical temporal distributions were designated by Huff curves, which provided characterizing storm mass curves, along with the relationship of intensityduration-frequency to determine storm intensity for 1-h in 2-year return period. Three types of LID units (rain barrel, infiltration trench, and vegetative swale) were selected to develop aggregate LID scenarios using the SWMM. The results indicated that, when compared with other field experiments, the SWMM successfully estimated change in flow discharge and suspended solid (SS) loss reflecting different storm patterns at the final outlet of and urbanized sub-catchment as well as the effects of LID practices. The performances of aggregate LID scenarios including lag time of peak runoff, peak runoff reduction, volume reduction, and SS loss reduction were sensitive to arrangement order and timeof-storm peak-to-storm duration. Scenario 5, which had the order of vegetative swale, rain barrel, and infiltration trench, showed the most effective serial arrangement, as it exhibited the more consistent results across the storm patters. This study thus provides insights into the effective design of aggregate LID scenarios considering different storm characteristics.
\end{abstract}

Keywords: Low impact development; Design storm; Storm water management model; Aggregate LID; Urban runoff

\footnotetext{
* Corresponding author.
} 